\title{
Solitary Splenic Metastasis After Surgically-treated Cervical Cancer - A Case Report and Literature Review
}

\author{
NICOLAE BACALBASA ${ }^{1}$, IRINA BALESCU ${ }^{2}$, MADALINA MARCU ${ }^{3}$, \\ DANA NUTI OPRESCU ${ }^{4}$ and ALEXANDRU FLORIN ANCA ${ }^{5}$ \\ ${ }^{1}$ Department of Obstetrics and Gynecology, Carol Davila University of \\ Medicine and Pharmacy, Bucharest, Romania; \\ ${ }^{2}$ Department of General Surgery, Ponderas Academic Hospital, Bucharest, Romania; \\ ${ }^{3}$ Department of Pathology, Ilfov County Hospital, Bucharest, Romania; \\ ${ }^{4}$ Department of Obstetrics and Gynecology, INSMC "Alessandrescu Resescu", Bucharest, Romania \\ ${ }^{5}$ Department of Obstetrics and Gynecology, University Emergency Hospital, Bucharest, Romania
}

\begin{abstract}
Background/Aim: Solitary metastases after surgically-treated cervical cancer are a rare entity, with only few cases described so far. Patient and Methods: We present the case of a 31-year-old patient diagnosed with a tumoral splenic lesion at 18 months after surgically-treated cervical cancer. Results: The patient was submitted to surgery, with a splenectomy being performed. The histopathological studies confirmed the presence of a squamous cell cervical cancer splenic metastasis. At one year follow-up after splenectomy, the patient is free of any recurrent disease. Conclusion: Solitary splenic metastases after surgicallytreated cervical cancer are rarely seen; however, this diagnostic should not be omitted whenever a medical history of cervical cancer is present.
\end{abstract}

Cervical cancer remains one of the most common gynecologic malignancies worldwide; although association of oncologic treatment is widely performed, a number of cases will develop, at a certain moment, distant metastases $(1,2)$. Unfortunately, most patients in this situation will be diagnosed with disseminated secondary lesions, being candidates only for palliative treatment. In rare cases, solitary metastases have been reported, transforming the patient into the perfect candidate for re-operation. We present the case of a 31-year-old patient diagnosed with an isolated splenic recurrence 18 months after surgically-treated cervical cancer.

This article is freely accessible online.

Correspondence to: Nicolae Bacalbașa, Department of Obstetrics and Gynecology, Carol Davila University of Medicine and Pharmacy, Dimitrie Racovita Street, no. 2, Bucharest, Romania. Tel: +40723540426, e-mail: nicolae_bacalbasa@yahoo.ro

Key Words: Cervical cancer, splenic metastasis, splenectomy.

\section{Case Report}

We present the case of a 31-year-old patient who initially presented to our service for pelvic pain and massive vaginal bleeding. At that moment, a cervical biopsy revealed the presence of a moderately differentiated squamous cell cervical cancer. The preoperative investigations revealed a stage IIB cervical tumor, so the patient was submitted to neoadjuvant chemotherapy and radiation therapy followed by surgery; a total radical hysterectomy en bloc, with bilateral adnexectomy and pelvic lymph node dissection was performed. The histopathological studies confirmed the presence of an area of $5 \mathrm{~mm}$ with 4-mm deep invasion with malignant transformation; in the meantime, the histopathological evaluation of the lymph nodes revealed the absence of tumoral invasion in none of the retrieved lymph nodes (eleven left side lymph nodes and seven right side lymph nodes). These findings classified the lesion as a T1a2, pNO, M0 cervical cancer. At 18 months follow-up, the patient was diagnosed with an isolated tumoral mass of $5 / 5 \mathrm{~cm}$ located in the splenic hylum, so the patient was re-operated. Intraoperatively, the diagnostic of solitary splenic lesion was confirmed, so the patient was submitted to splenectomy (Figures 1-5). The postoperative course was uneventful, with the patient being discharged in the fifth postoperative day. The histopathological study revealed the presence of a $5 / 5 \mathrm{~cm}$ lesion with a typical aspect of a splenic metastasis of a moderately differentiated squamous cell cervical cancer. One month after discharge, the patient was submitted to adjuvant chemotherapy consisting of six cycles of cisplatin and paclitaxel. At one year follow-up, the patient is free of any recurrent disease or distant metastases.

\section{Discussion}

Cervical cancer has a high propensity of local spread, after destroying the natural compartmental borders, leading to the apparition of pelvic masses involving the urinary bladder and/or 


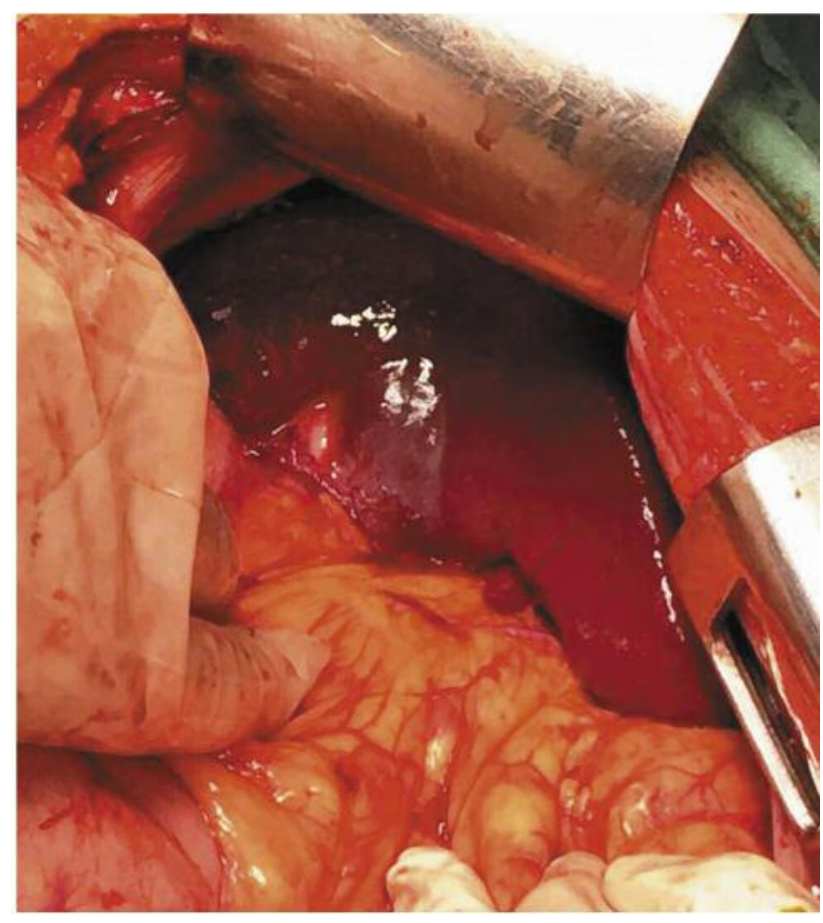

Figure 1. Initial aspect of the tumor: solid lesion development on the upper pole of the spleen.

the rectum, followed by lymphatic spread into the regional and distant lymphatic chains (3-7). Hematogenous spread is a rare pathway of dissemination, leading to the apparition of parenchimatous lesions, with the most commonly reported being located in lungs, bones or liver $(2,8)$. In Fagundes et al.'s study (8), the authors reported that the most common site of distant relapses is the lung (in $21 \%$ of cases) followed by paraaortic lymph nodes (in 11\% of cases), abdominal cavity (in $8 \%$ of cases) and supraclavicular lymph nodes (in $7 \%$ of cases). The same study demonstrated that the type of relapse is significantly influenced by the initial FIGO stage at diagnosis: patients diagnosed in early stages of the disease are more likely to develop local recurrences, while cases diagnosed in advanced stages are more likely to develop distant or distant and local recurrences; in the meantime, once the distant relapse is diagnosed, the overall survival rate is of only 12 weeks $(9,10)$. The extremely short overall survival after diagnosis of distant metastases has been explained through the fact that, most often, these cases are diagnosed with systemic relapse, transforming the patient into a candidate for palliative oncological treatment. Fortunately, in our case, the patient was diagnosed with a solitary lesion, so she was successfully submitted to surgery.

The improvement of surgical techniques in patients presenting hepato-bilio-pancreatic or splenic lesions leads to the safe association of such resections in cases presenting both primary and metastatic lesions, inducing a significant survival benefit. Due to these aspects, extended upper

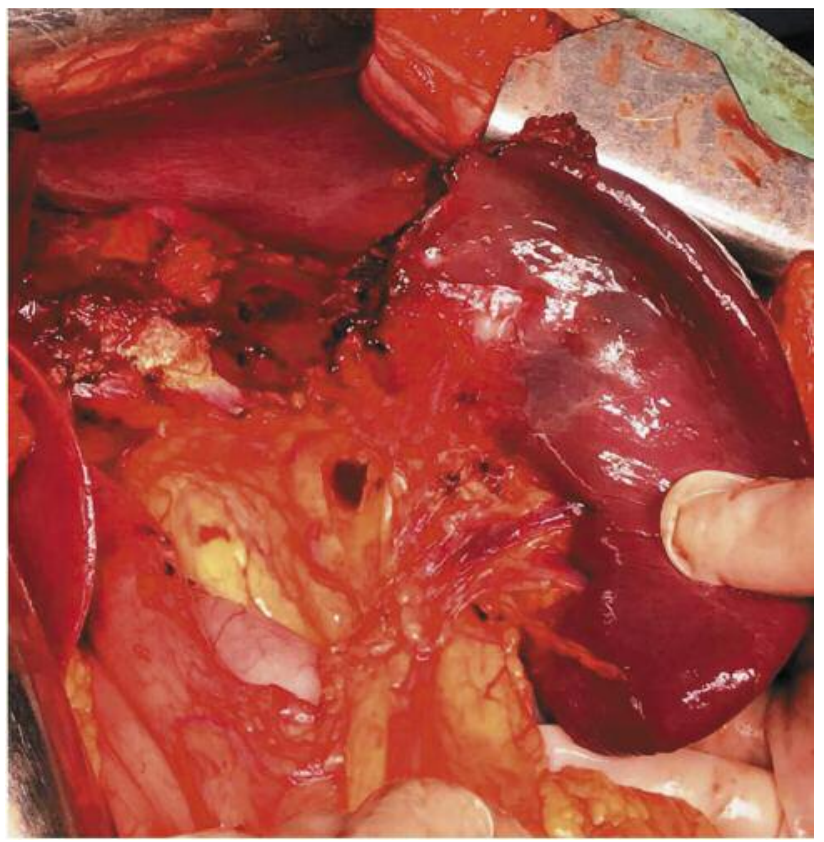

Figure 2. Aspect of the tumor after lateral mobilization of the spleen.

abdominal resections have been widely reported initially in cases presenting metastatic lesions with ovarian origin followed by other primaries, such as cervical cancer, with good results in regard with long-term outcomes (2, 11-20).

Splenic metastases from cervical cancer represent a rare situation, with the first reported case coming from Brufman et al. in 1977 (21). According to Dixit et al., who reported in December 2016 a case of an isolated splenic metastasis at 17 months after completing the oncological treatment for squamous cell cervical cancer, only 11 cases had been published before, with their case being the 12th reported ever (22).

Moreover, due to the rarity of this particular situation, no case series has been reported so far; the largest series of patients presenting splenic metastases from cervical cancer originate from autopsy studies by Sotto et al. who reported eight cases of splenic lesions among 108 cases with cervical cancer (23). The main patterns of splenic involvement include splenic artery, splenic vein and lymphatic dissemination (24). In the meantime, the low number of cases diagnosed with splenic metastases can be explained through multiple mechanisms, such as the tortuosity of the splenic artery, presence of splenic capsule, rhythmic contractions of the spleen, or through the antineoplastic properties of the splenic parenchyma (25).

When it comes to clinical symptoms, patients with splenic metastases remain most often asymptomatic for a long period of time or present atypical complaints, such as left hypochondria pain (8). 


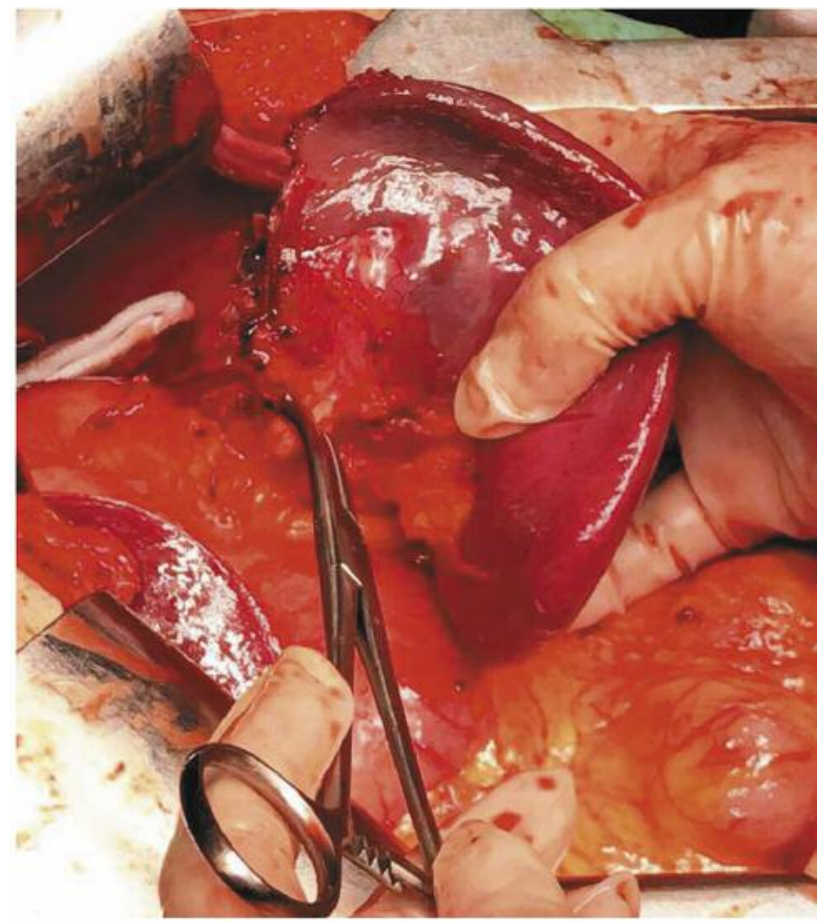

Figure 3. Medial dissection of the spleen; identification of vascular pedicles.

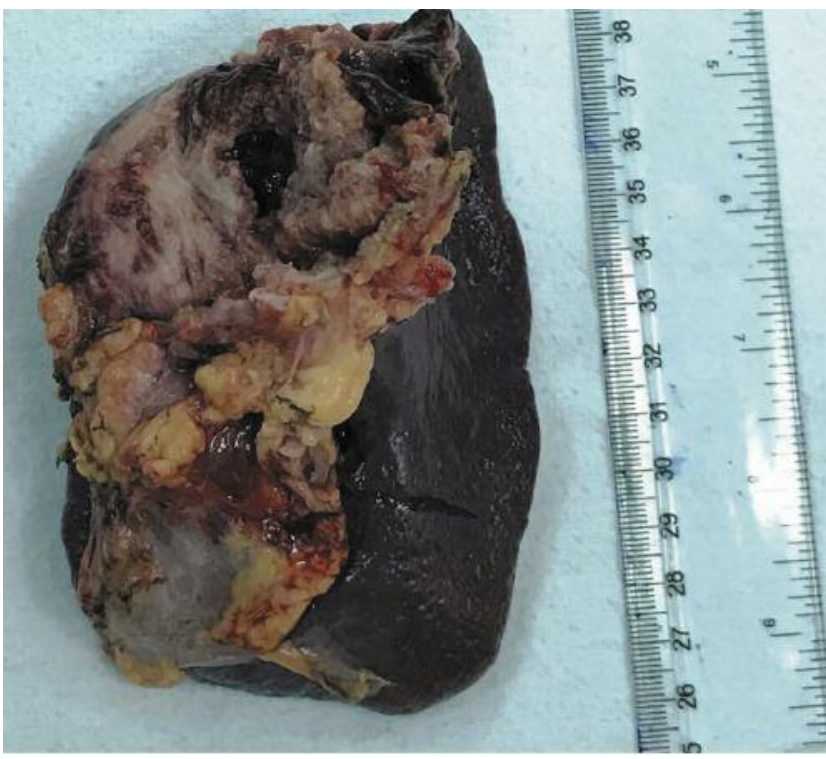

Figure 4. Specimen of splenectomy presenting a 5/5/3 cm tumor at the upper pole.

As for the rationale of associating adjuvant chemotherapy, most authors consider that it should be taken in consideration because the splenic lesion is in fact a distant metastasis necessitating systemic therapy $(26,27)$. However, the presence

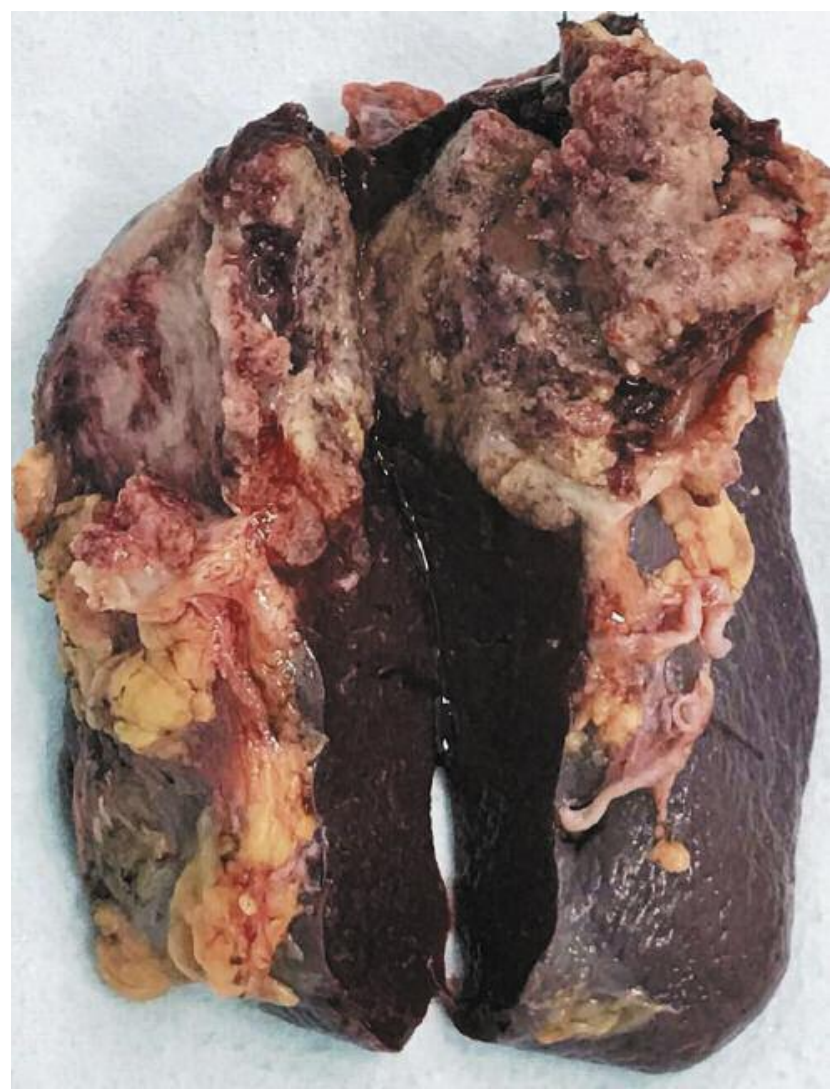

Figure 5. The specimen of splenectomy is transected: apparition of a large tumoral lesion at the upper pole of the spleen.

of an isolated distant metastasis is considered by some authors as a sign of a less aggressive biological subtype of the tumor as compared to those cases that present disseminated lesions, thus transforming the patient into the perfect candidate for surgery $(28,29)$.

\section{Conclusion}

Splenic metastases from cervical cancer are rarely seen; however, this particular situation should not be omitted whenever the patient has a medical history of cancer. In certain cases, when isolated lesions are encountered, splenectomy can be safely performed with good results in terms of survival. However, due to the paucity of cases reported so far, no specific data regarding long-term outcomes are available for the moment.

\section{Acknowledgements}

This work was supported by a grant of the Romanian National Authority for Scientific Research and Innovation, CNCS UEFISCDI, project number PN-II-RU-TE-2014-4-2533. 


\section{References}

1 Taga S, Sawada M, Nagai A, Yamamoto D and Hayase R: Splenic metastasis of squamous cell carcinoma of the uterine cervix: A case report and review of the literature. Case Rep Obstet Gynecol 2014: 798948, 2014.

2 Bacalbasa N, Balescu I, Dima S and Popescu I: Hepatic resection for liver metastases from cervical cancer is safe and may have survival benefit. Anticancer Res 36: 3023-3027, 2016.

3 Hockel M, Hentschel B and Horn LC: Association between developmental steps in the organogenesis of the uterine cervix and locoregional progression of cervical cancer: A prospective clinicopathological analysis. Lancet Oncol 15: 445-456, 2014.

4 Hockel M, Horn LC and Einenkel J: (Laterally) extended endopelvic resection: Surgical treatment of locally advanced and recurrent cancer of the uterine cervix and vagina based on ontogenetic anatomy. Gynecol Oncol 127: 297-302, 2012.

5 Hockel M, Einenkel J and Horn LC: Paraaortic lymphatic spread in cervical cancer. Gynecol Oncol 127: 677-678, 2012.

6 Bacalbasa N, Balescu I and Tomescu D: Partial cystectomy with distal ureteral resection and re-implantation for locally invasive cervical cancer. Anticancer Res 35: 5539-5542, 2015.

7 Bacalbasa $\mathrm{N}$ and Balescu I: Palliative pelvic exenteration for pelvic recurrence invading the sciatic foramen with chronic cutaneous perineal fistula after radical surgery for cervical cancer: A case report. Anticancer Res 35: 4877-4880, 2015.

8 Carlson V, Delclos L and Fletcher GH: Distant metastases in squamous-cell carcinoma of the uterine cervix. Radiology 88 : 961-966, 1967.

9 Fagundes H, Perez CA, Grigsby PW and Lockett MA: Distant metastases after irradiation alone in carcinoma of the uterine cervix. Int J Radiat Oncol Biol Phys 24: 197-204, 1992.

10 Quinn MA, Benedet JL, Odicino F, Maisonneuve P, Beller U, Creasman WT, Heintz AP, Ngan HY and Pecorelli S: Carcinoma of the cervix uteri. FIGO 26th annual report on the results of treatment in gynecological cancer. Int $\mathbf{J}$ Gynaecol Obstet 95(Suppl 1): S43-103, 2006.

11 Bacalbasa N, Balescu I, Dima S, Brasoveanu V and Popescu I: Pancreatic resection as part of cytoreductive surgery in advanced-stage and recurrent epithelial ovarian cancer - A single-center experience. Anticancer Res 35: 4125-4129, 2015.

12 Eisenkop SM, Spirtos NM, Friedman RL, Lin WC, Pisani AL and Perticucci S: Relative influences of tumor volume before surgery and the cytoreductive outcome on survival for patients with advanced ovarian cancer: A prospective study. Gynecol Oncol 90: 390-396, 2003.

13 Mirancea GV, Morosanu AM, Carniciu S, Dima S, Bacalbasa N, Popescu I, Ionescu-Tirgoviste C and Mirancea N: Relevant infrastructural alterations in a pancreatic neuroendocrine tumor: An insulinoma case. Rom J Morphol Embryol 55: 659-668, 2014.

14 Bacalbasa N, Dima S, Balescu I, David L, Brasoveanu V and Popescu I: Results of primary cytoreductive surgery in advanced-stage epithelial ovarian cancer: A single-center experience. Anticancer Res 35: 4099-4104, 2015.

15 Eisenhauer EL, Abu-Rustum NR, Sonoda Y, Levine DA, Poynor EA, Aghajanian C, Jarnagin WR, DeMatteo RP, D'Angelica MI, Barakat RR and Chi DS: The addition of extensive upper abdominal surgery to achieve optimal cytoreduction improves survival in patients with stages IIIC-IV epithelial ovarian cancer. Gynecol Oncol 103: 1083-1090, 2006.
16 Bacalbasa N, Balescu I, Dima S, Brasoveanu V and Popescu I: Splenectomy as part of cytoreductive surgery in recurrent epithelial ovarian cancer. Anticancer Res 35: 5097-5101, 2015.

17 Bacalbasa N, Balescu I, Dima S, Brasoveanu V and Popescu I: Hematogenous splenic metastases as an independent negative prognosis factor at the moment of primary cytoreduction in advanced stage epithelial ovarian cancer - A single center experience. Anticancer Res 35: 5649-5654, 2015.

18 Brasoveanu V, Anghel C, Barbu I, Pautov M, Ionescu MI, Motthor M, Balescu I, Dima $S$ and Bacalbasa N: Pancreatoduodenectomy en bloc with portal and superior mesenteric artery resection - A case report and literature review. Anticancer Res 35: 1613-1618, 2015.

19 Bacalbasa N, Dima S, Brasoveanu V, David L, Balescu I, Purnichescu-Purtan R and Popescu I: Liver resection for ovarian cancer liver metastases as part of cytoreductive surgery is safe and may bring survival benefit. World J Surg Oncol 13: 235, 2015.

20 Bacalbasa N, Balescu I, Dima S and Popescu I: Long-term survivors after liver resection for ovarian cancer liver metastases. Anticancer Res 35: 6919-6923, 2015.

21 Brufman G, Biran S, Goldschmidt Z and Freund U: Solitary metastatic involvement of the spleen in squamous cell carcinoma of the cervix. Harefuah 92: 349-350, 1977.

22 Dixit J, Mohammed N and Shetty P: Splenic metastasis from cancer of uterine cervix-a rare case. Indian J Surg Oncol 7: 479483, 2016.

23 Laurenti MD, Sotto MN, Corbett CE, da Matta VL and Duarte MI: Experimental visceral leishmaniasis: Sequential events of granuloma formation at subcutaneous inoculation site. Int J Exp Pathol 71: 791-797, 1990.

24 Pang LC: Solitary recurrent metastasis of squamous cell carcinoma of the uterine cervix in the spleen: case report. South Med J 97: 301-304, 2004.

25 Koh YS, Kim JC and Cho CK: Splenectomy for solitary splenic metastasis of ovarian cancer. BMC Cancer 4: 96, 2004.

26 Moore DH, Blessing JA, McQuellon RP, Thaler HT, Cella D, Benda J, Miller DS, Olt G, King S, Boggess JF and Rocereto TF: Phase III study of cisplatin with or without paclitaxel in stage IVB, recurrent, or persistent squamous cell carcinoma of the cervix: A gynecologic oncology group study. J Clin Oncol 22: 3113-3119, 2004.

27 Thigpen T, Shingleton H, Homesley H, Lagasse L and Blessing $\mathrm{J}$ : Cis-platinum in treatment of advanced or recurrent squamous cell carcinoma of the cervix: A phase II study of the Gynecologic Oncology Group. Cancer 48: 899-903, 1981.

28 Di D, V, Palaia I, Perniola G, Polidori N, Burratti M, Besharat A and Panici PB: Splenic metastasis from cervical cancer: Case report and review of the literature. J Obstet Gynaecol Res 36: 887-890, 2010.

29 Kim JH, Choi YD, Lee JH, Nam JH, Juhng SW, Koh YS, Cho CK, Choi C: Solitary splenic metastases from uterine cervical cancer: Case reports and review of the literature. Korean J Pathol 42: 317-322, 2008 